\title{
Widespread bleaching in the One Tree Island lagoon (Southern Great Barrier Reef) during record-breaking temperatures in $\mathbf{2 0 2 0}$
}

\author{
Megan K. B. Nolan (1) S Sebastian Schmidt-Roach • \\ Andrew R. Davis • Manuel Aranda • \\ Emily J. Howells
}

Received: 21 April 2021 / Accepted: 22 July 2021 / Published online: 21 August 2021

(C) The Author(s), under exclusive licence to Springer Nature Switzerland AG 2021

\begin{abstract}
The global marine environment has been impacted significantly by climate change. Ocean temperatures are rising, and the frequency, duration and intensity of marine heatwaves are increasing, particularly affecting coral reefs. Coral bleaching events are becoming more common, with less recovery time between events. Anomalous temperatures at the start of 2020 caused widespread bleaching across the Great Barrier Reef (GBR), extending to southern, previously less affected reefs such as One Tree Island. Here, nine video transects were conducted at One Tree Island, in the Capricorn Bunker Group, and analysed for community composition and diversity, and the extent of bleaching across taxa. Average live hard coral cover across the area was $11.62 \%$, and almost half of this was identified as severely bleached. This bleaching event is concerning as it occurred in an area previously considered a potential refuge for
\end{abstract}

Supplementary information The online version contains supplementary material available at https://doi. org/10.1007/s10661-021-09330-5.

M. K. B. Nolan $(\bowtie) \cdot$ S. Schmidt-Roach $\cdot$ M. Aranda Red Sea Research Centre, King Abdullah University of Science and Technology, Thuwal 23955-6900,

Saudi Arabia

e-mail: megannolan95@ outlook.com

A. R. Davis - E. J. Howells

Centre for Sustainable Ecosystem Solutions and School of Earth, Atmospheric and Life Sciences, University of Wollongong, Wollongong, NSW 2522, Australia corals and associated fauna from the risks of climate warming. Due to the global impacts of COVID-19 during 2020, this report provides one of potentially few monitoring efforts of coral bleaching.

Keywords Coral reef $\cdot$ Bleaching $\cdot$ Great Barrier Reef · One Tree Island

\section{Introduction}

The significance of coral reefs is unquestioned, both for ecosystem functioning (e.g. Glynn \& Enochs, 2011; Lefcheck et al., 2019) and local human populations (e.g. Spalding et al., 2017; JanuchowskiHartley et al., 2020). Due to climate change, marine heatwaves are increasing in frequency and duration (Oliver et al., 2018), with some lasting for years at a time (Di Lorenzo \& Mantua, 2016). Such heatwaves are causing mass coral bleaching and mortality events (Hoegh-Guldberg, 2011; Couch et al., 2017), including among coral populations previously considered thermally tolerant (Le Nohaiic et al., 2017).

The Great Barrier Reef (GBR) has experienced extensive bleaching, and the recent bleaching event in 2020, a non El Niño year, is the third widespread event since 2015 (Hughes et al., 2018). The most recent bleaching events affecting the GBR have occurred at regional scales, with the 2016 event most severely impacting reefs in the Far North and Northern GBR (Wolanski et al., 2017) and the 2017 event 
mostly affecting reefs in the North and Central GBR (Hughes et al., 2019). These events spared the reefs in the Southern GBR, although localised bleaching events have been recorded in earlier years (e.g. Booth \& Beretta, 2002; Ortiz et al., 2009). Here, we report on bleaching on the Southern GBR at One Tree Island during 2020.

Due to the worldwide COVID-19 pandemic and resulting travel restrictions, in situ observations of the recent GBR bleaching event have been limited. Many research and boating activities were stopped, preventing important quantitative surveys of bleaching impacts (Bates et al., 2020), and increasing the value of any records collected during this time. Here, we analyse video transects taken in February 2020, shortly before research activities were restricted, showing the severity of bleaching at One Tree Island in the Southern GBR.

\section{Materials and methods}

Coral video transects were conducted on 22 February 2020 at three sites in the southern part of the main and most southerly lagoon of One Tree Island $\left(23^{\circ} 30^{\prime} 30^{\prime \prime} \mathrm{S}, 152^{\circ} 05^{\prime} 30^{\prime \prime} \mathrm{E}\right)$. One Tree Island is located in the Capricorn and Bunker Group in the Southern Great Barrier Reef (Fig. 1). An Olympus TG 5 camera with Olympus housing was used to record the videos, approximately $1 \mathrm{~m}$ above a $30-\mathrm{m}$ transect tape placed at uniform depth along the reef flat. Video coverage extended roughly $1 \mathrm{~m}$ to the right of the tape, and both sides were filmed. Hence, the total coverage of each of the three transects and each of the three sites (for a total of nine transects) was 60 $\mathrm{m}^{2}$.

For each video, 60 frames were extracted at equal time intervals using Video Image Master Pro (A4Video, 2002). Using CPCe (Coral Point Count with Excel extension; Kohler \& Gill, 2006), 50 points were added randomly to each image, and the coral genera or substratum type directly below that point was identified. The genera Goniopora and Alveopora were grouped together as the photos did not provide enough detail to confidently distinguish between these genera. As both genera belong to the same functional group (stony coral), this grouping should not affect the results of this study. Substratum was recorded as sand, rock, old dead coral or rubble; the latter was used for broken dead fragments of coral. Tape or (a)

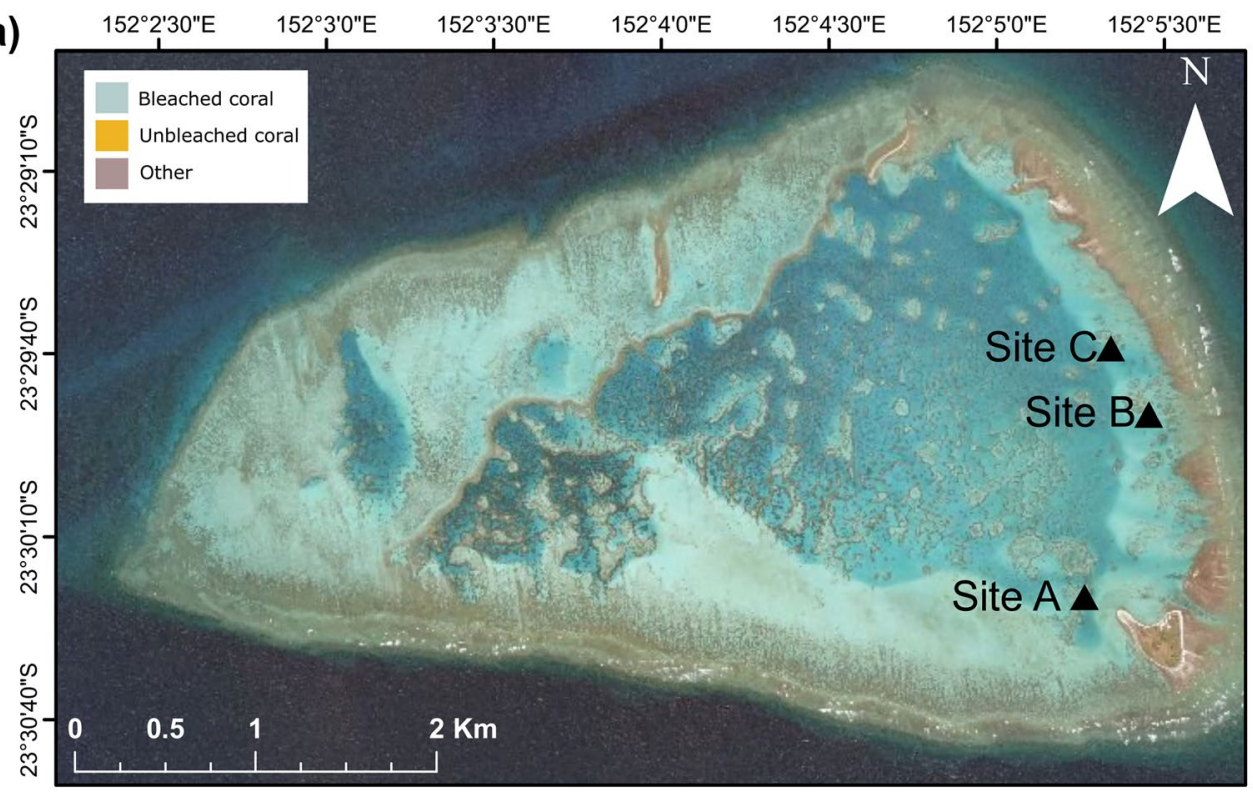

(b)

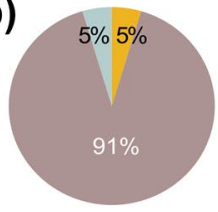

(c)

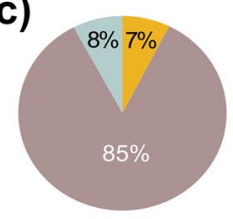

(d)

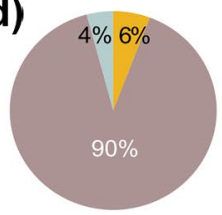

Fig. 1 Coral cover on One Tree Island. a Map of study area indicating site locations, and pie charts showing per cent cover of bleached and unbleached coral for $\mathbf{b}$ site A, $\mathbf{c}$ site B and $\mathbf{d}$ site C. Three transects were analysed for each site. Satellite image sources: Esri and Maxar 
other were used if the point fell on the transect tape, or on a section of the photo obscured by an air bubble on the camera lens. Macrofauna, invertebrates and soft coral were also identified (Fig. S1). For points that fell over live hard coral, the level of bleaching was determined and noted, based on the CoralWatch colour chart (Siebeck et al., 2006; Fig. S1). For this quantitative analysis, corals with a CoralWatch score of B1, C1, D1 or E1 were assumed to be bleached, while those with a higher numerical score, regardless of letter, were considered unbleached. This ensures naturally pale colonies are not counted as bleached. However, it also excludes naturally darker colonies which have bleached considerably, but are not completely white, resulting in a conservative estimate of bleached colonies. Frames were all analysed by the same researcher (M.K.B.N.) to reduce observer bias.

Live hard coral cover and Simpson's diversity index (Simpson, 1949) were estimated. The extent of bleaching was summarised by species, by transect and by site, using both number of colonies and per cent cover. All analyses were carried out using R ( R version 3.6.0; $\mathrm{R}$ Core Team, 2017).

\section{Results}

Across all transects, we recorded an average live hard coral cover of $11.62 \%$ ( \pm 3.40 standard deviation, SD), which ranged from $9.60 \%$ ( $\pm 2.03 \mathrm{SD})$ to $15.25 \%$ ( $\pm 0.99 \mathrm{SD}$ ) among the three survey sites (Fig. 1). These estimates of live coral cover are considerably lower than those reported from a nearby site perpendicular to the reef flat in 2013 by Shaw et al. (2014). No significant coral mortality was observed at the time of the survey, but COVID-19 restrictions prevented any follow-up surveys on mortality. Overall, twenty scleractinian coral genera were identified, and the total number of colonies identified for each genus ranged from one (Pectinia) to 195 (Porites: Fig. 2). Biodiversity was similar between all nine transects (Simpson's diversity index; $0.76 \pm 0.06 \mathrm{SD}$; Simpson, 1949).

On average, almost half of the live hard coral cover surveyed was bleached $(47.91 \% \pm 11.28$; Fig. 3; Table S1). Although this is a severe level of bleaching, it is not above the $60 \%$ threshold set by Hughes et al. (2017) for 'extreme' bleaching. Most bleaching was observed on transect $1(65.82 \%)$, and least was seen on transect 3 (31.36\%); both within site A. This demonstrates that bleaching rates can vary over small scales, supporting previous observations in other locations (Lenihan et al., 2008). Further, bleaching rates varied among genera as described in previous studies (reviewed in Hoey et al., 2016). For example, Anacropora and Pectinia were 100\% bleached, closely followed by Acropora, Seriatopora and Montipora, which each showed $>80 \%$ bleaching. Conversely, several genera showed minimal bleaching $(<$ 10\%: Echinopora and Porites) or no bleaching (0\%: Dipsastraea, Favites, Fungia, Goniastrea, Lobophyllia and Platygyra). It is important to note that some of these genera have a small sample size (particularly those with $100 \%$ bleaching records: Fig. 3) and should therefore be regarded with caution.

\section{Discussion}

The observed severe bleaching in the One Tree Island lagoon followed months of regionally recordbreaking temperatures. Mean air temperatures recorded between November 2019 and February 2020 at the nearby station of Seventeen Seventy were the hottest since records began in the 1980s (Commonwealth of Australia Bureau of Meteorology, 2020). Daily average water temperatures in the lagoon in February were up to $3.2{ }^{\circ} \mathrm{C}$ higher in 2020 than over the previous decade. Additionally, temperature anomalies (above $27.5{ }^{\circ} \mathrm{C}$ ) during February 2020 were recorded every day (29 days) compared to 14 and 8 days in 2018 and 2019 respectively, or 0 days in the long-term average where data was available (2000-2009 and 2017-2018: Fig. 4a). In the month following this data collection, sea surface temperatures sharply dropped from a daily average of approximately 29 to $26^{\circ} \mathrm{C}$ (Fig. 4b), likely providing relief for the affected colonies. However, coral recovery is a complex and variable process, which differs with species and colony size (Baird \& Marshall, 2002) and is further influenced by physical characteristics, such as the frequency of cyclones or the presence of Crown of Thorns starfish. Coral recovery on the GBR has declined significantly in recent years 


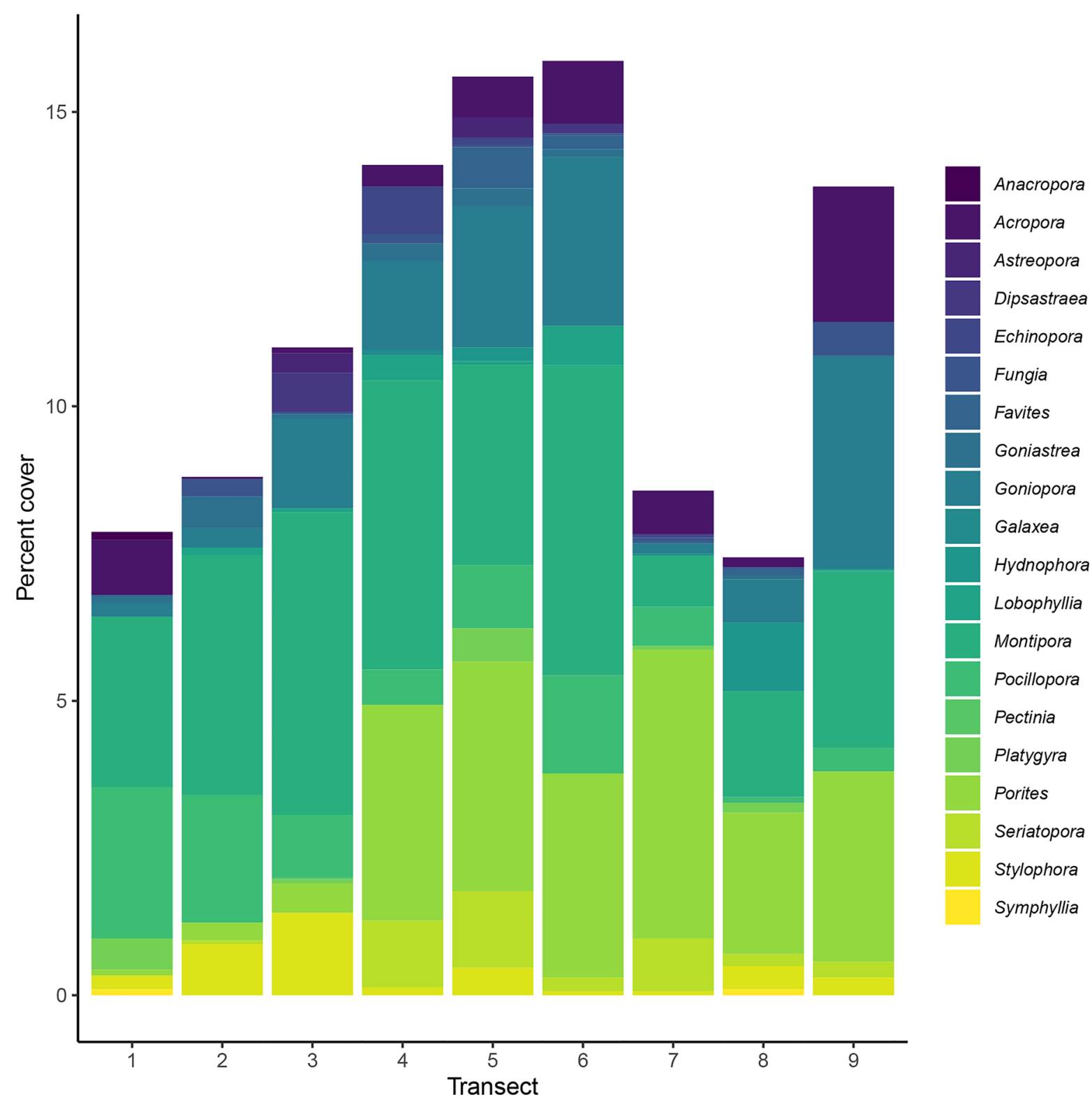

Fig. 2 Taxonomic variation in coral cover among transects. Number of points corresponds to per cent cover of each coral genus as recorded using CPCe. Column heights represent differing overall hard coral cover on the transect

(Ortiz et al., 2018) and may continue to decline in the future as the increasing frequency of bleaching events reduces recovery time between disturbances (Dietzel et al., 2020).

The Southern GBR has been largely unaffected by mass bleaching events in the past (Kennedy et al., 2018). This bleaching event is the first major bleaching to affect One Tree Island since 1998 where 10-30\% of corals bleached (Berkelmans et al., 2004a, b). Due to the relatively low bleaching incidence in the past, the southern GBR has been suggested as an area with potential to withstand temperature-related 


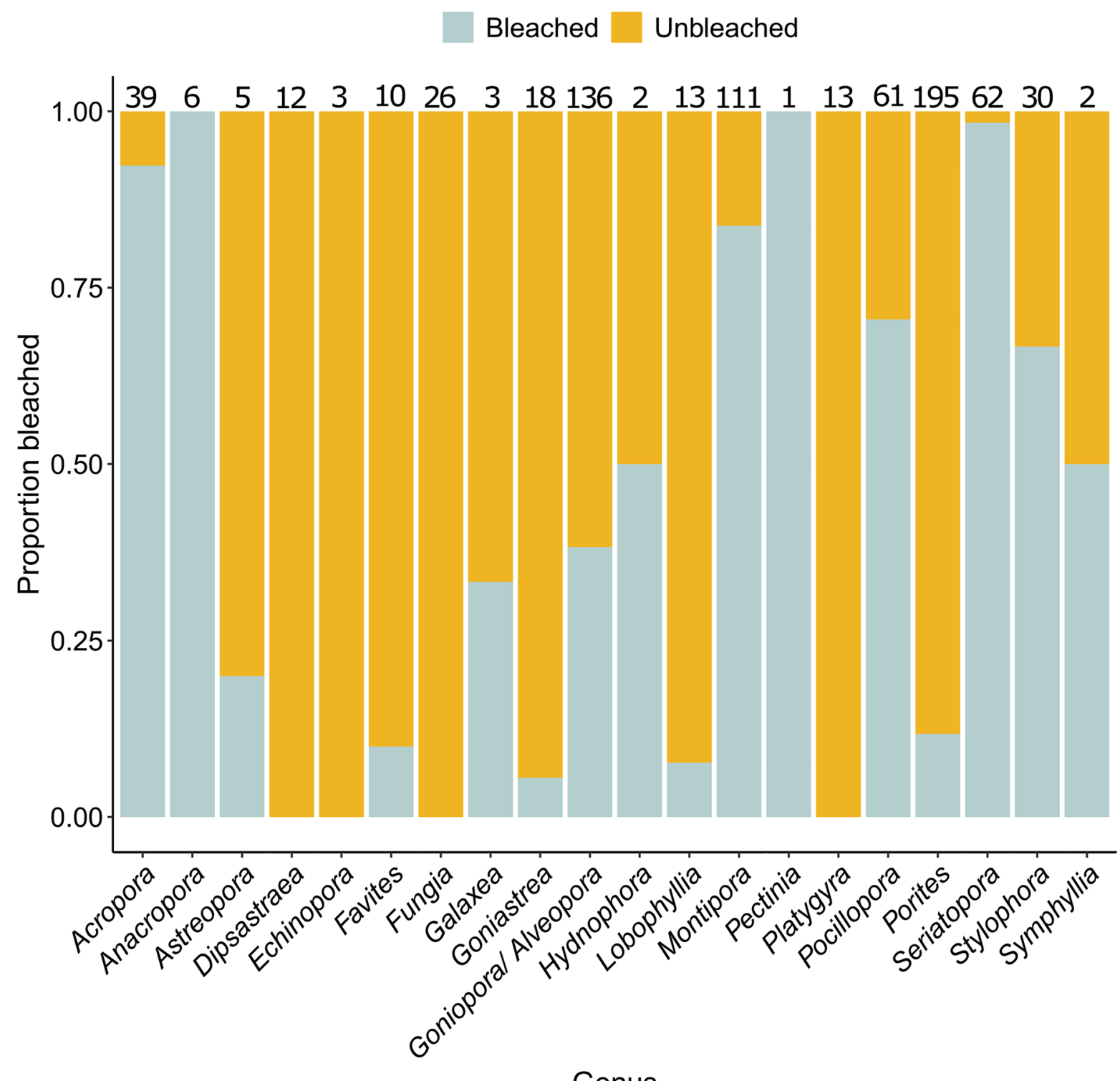

Fig. 3 Proportion of bleaching for each genus. For 20 genera, the per cent cover that was identified as bleached (CoralWatch score 1), or unbleached (CoralWatch score 2-6). Labels at the top of bars show the number of recorded colonies for each genus

coral cover loss. This is in part due to restocking of coral larvae from further north, where individuals are adapted to higher temperatures (Matz et al., 2020). The present study has shown that these Southern reefs are still susceptible to widespread bleaching events.
It will be important to closely follow the recovery of Southern GBR reefs, potentially looking at One Tree Island as a case study, in order to understand the potential of these reefs to act as a refuge under future climate scenarios. 

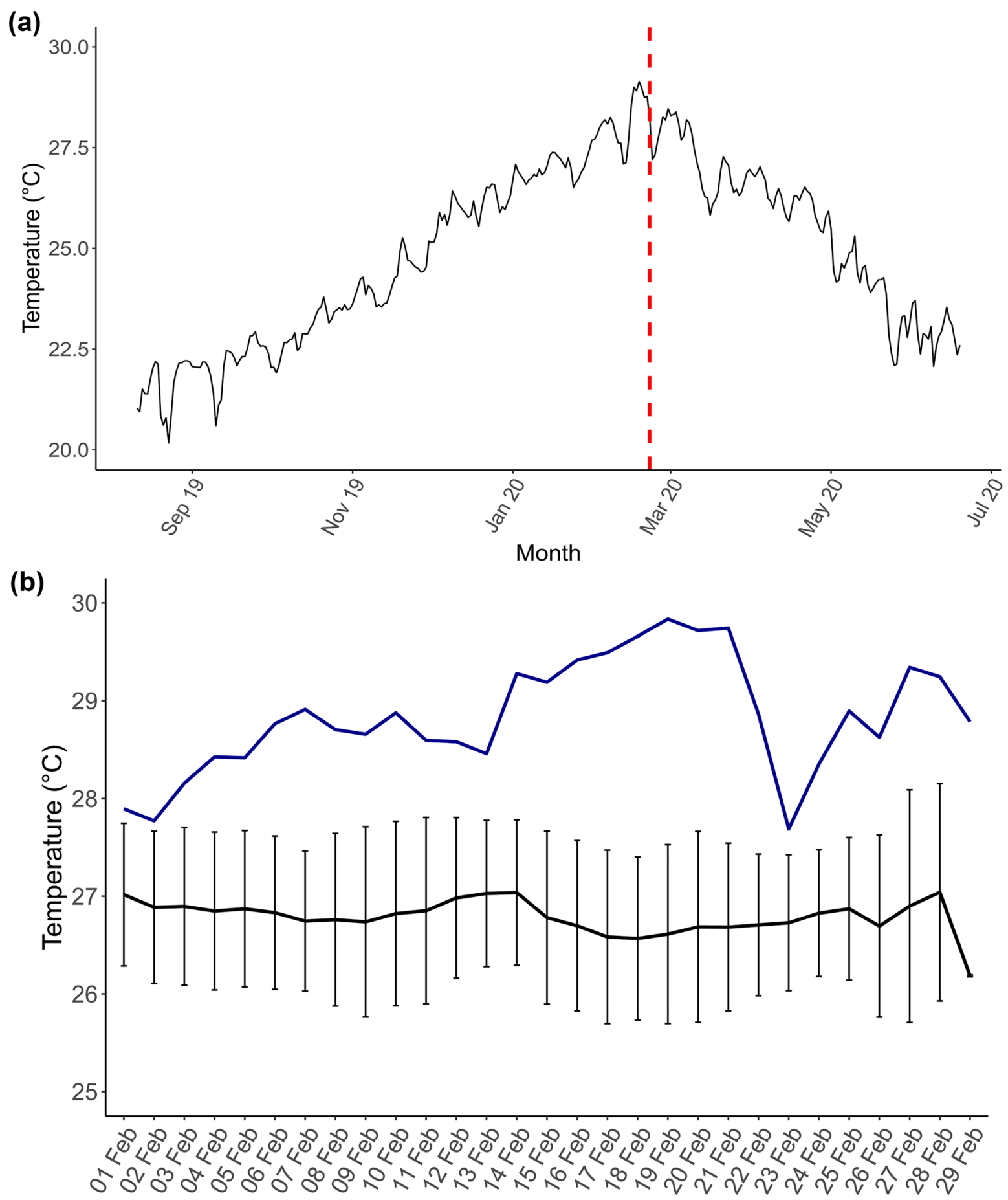

\section{Date}

Fig. 4 Temperature patterns at One Tree Island. a Data from 11 August 2019 to 20 June 2020. Data recorded at $2.3 \mathrm{~m}$ depth at 00:00 daily. Dashed vertical line indicates date when transects were recorded. Raw data downloaded from AIMS (data. aims.gov.au). b Temperature data from One Tree Island Third Lagoon for February 2020 (upper blue line) compared to long-term February averages for 2000-2009 and 2017-2018 (excluding 7 years where records were unavailable; lower black line). Error bars show standard deviation for long term data. Data from temperature loggers deployed by One Tree Island Research Station 
Acknowledgements We thank One Tree Island Research Station for the long-term temperature logger data and station managers, Ruby Holmes and Heinrich Breuer, for the fieldwork support.

Funding Funding was provided by a Hermon Slade Foundation grant (\#HSF 18-7) awarded to E. J. Howells and KAUST baseline funding awarded to M. Aranda.

Data availability The datasets generated during and/or analysed during the current study are available from the corresponding author on reasonable request.

\section{Declarations}

Competing interests The authors declare no competing interests.

\section{References}

A4Video. (2002). Video Image Master Pro. https://www.a4video. com/downloads.htm

Baird, A., \& Marshall, P. (2002). Mortality, growth and reproduction in scleractinian corals following bleaching on the Great Barrier Reef. Marine Ecology Progress Series, 237, 133-141.

Bates, A. E., Primack, R. B., Moraga, P., Duarte, C. M. (2020). COVID-19 pandemic and associated lockdown as a "Global Human Confinement Experiment" to investigate biodiversity conservation. Biological Conservation, 248.

Berkelmans, R., De'ath, G., Kininmonth, S., \& Skirving, W. J. (2004a). A comparison of the 1998 and 2002 coral bleaching events on the Great Barrier Reef: spatial correlation, patterns, and predictions. Coral Reefs, 23, 74-83.

Berkelmans, R., De'ath, G., Kininmonth, S., \& Skirving, W. J. (2004b) GBR - coral mass bleaching extent in 1998 and 2002 by aerial surveys (MTSRF 1.1.5, AIMS). https://eatlas. org.au/data/uuid/2a17791d-8175-481b-8d31-c25f02e66ef6

Booth, D. J., \& Beretta, G. A. (2002). Changes in a fish assemblage after a coral bleaching event. Marine Ecology Progress Series, 245, 205-212.

Commonwealth of Australia Bureau of Meteorology. (2020). Monthly mean maximum temperature. https://www.bom. gov.au/jsp/ncc/cdio/weatherData/av?p_nccObsCode $=$ $36 \& p \_d i s p l a y \_t y p e=d a t a F i l e \& p \_s t a r t Y e a r=\& p \_c=\& p \_$ stn_num $=039314$

Couch, C. S., Burns, J. H. R., Liu, G., Steward, K., Gutlay, T. N., Kenyon, J., Eakin, C. M., Kosaki, R. K. (2017). Mass coral bleaching due to unprecedented marine heatwave in Papahānaumokuākea Marine National Monument (Northwestern Hawaiian Islands). PLoS One, 12.

Dietzel, A., Bode, M., Connolly, S. R., \& Hughes, T. P. (2020). Long-term shifts in the colony size structure of coral populations along the Great Barrier Reef. Proceeding of the Royal Society B: Biological Sciences, 287, 20201432.

Di Lorenzo, E., \& Mantua, N. (2016). Multi-year persistence of the 2014/15 North Pacific marine heatwave. Nature Climate Change, 6, 1042-1047.
Glynn, P. W., \& Enochs, I. C. (2011). Invertebrates and their roles in coral reef ecosystems. Coral Reefs: An Ecosystem in Transition. Springer Netherlands, 273-325.

Hoegh-Guldberg, O. (2011). Coral reef ecosystems and anthropogenic climate change. Regional Environmental Change, 11, 215-227.

Hoey, A. S., Howells, E., Johansen, J. L., Hobbs, J. P. A., Messmer, V., McCowan, D. M., Wilson, S. K., \& Pratchett, M. S. (2016). Recent advances in understanding the effects of climate change on coral reefs. Diversity, 8, 12 .

Hughes, T. P., Kerry, J. T., Álvarez-Noriega, M., Álvarez-Romero, J. G., Anderson, K. D., Baird, A. H., Babcock, R. C., Beger, M., Bellwood, D. R., Berkelmans, R., Bridge, T. C., Butler, I. R., Byrne, M., Cantin, N. E., Comeau, S., Connolly, S. R., Cumming, G. S., Dalton, S. J., Diaz-Pulido, G., ... \& Wilson, S. K. (2017). Global warming and recurrent mass bleaching of corals. Nature, 543, 373-377.

Hughes, T. P., Kerry, J. T., Connolly, S. R., Baird, A. H., Eakin, C. M., Heron, S. F., Hoey, A. S., Hoogenboom, M. O., Jacobson, M., Liu, G., Pratchett, M. S., Skirving, W., \& Torda, G. (2019). Ecological memory modifies the cumulative impact of recurrent climate extremes. Nature Climate Change, 9, 40-43.

Hughes, T. P., Kerry, J. T., \& Simpson, T. (2018). Large-scale bleaching of corals on the Great Barrier Reef. Ecology, 99, 501 .

Januchowski-Hartley, F. A., Vigliola, L., Maire, E., Kulbicki, M., Mouillot, D. (2020). Low fuel cost and rising fish price threaten coral reef wilderness. Conservation Letters.

Kennedy, E. V., Ordoñez, A., \& Diaz-Pulido, G. (2018). Coral bleaching in the southern inshore Great Barrier Reef: a case study from the Keppel Islands. Marine Freshwater Research, 69, 191.

Kohler, K. E., \& Gill, S. M. (2006). Coral Point Count with Excel extensions (CPCe): A Visual Basic program for the determination of coral and substrate coverage using random point count methodology. Computers and Geosciences, 32, 1259-1269.

Lefcheck, J. S., Innes-Gold, A. A., Brandl, S. J., Steneck, R. S., Torres, R. E., \& Rasher, D. B. (2019). Tropical fish diversity enhances coral reef functioning across multiple scales. Science Advances, 5:eaav6420.

Lenihan, H., Adjeroud, M., Kotchen, M., Hench, J., \& Nakamura, T. (2008). Reef structure regulates small-scale spatial variation in coral bleaching. Marine Ecology Progress Series, 370, 127-141.

Le Nohaï, M., Ross, C. L., Cornwall, C. E., Comeau, S., Lowe, R., McCulloch, M. T., \& Schoepf, V. (2017). Marine heatwave causes unprecedented regional mass bleaching of thermally resistant corals in northwestern Australia. Scientific Reports, 7.

Matz, M. V., Treml, E. A., \& Haller, B. C. (2020). Estimating the potential for coral adaptation to global warming across the Indo-West Pacific. Global Change Biology, 26, 3473-3481.

Oliver, E. C. J., Donat, M. G., Burrows, M. T., Moore, P. J., Smale, D. A., Alexander, L. V., Benthuysen, J. A., Feng, M., Sen Gupta, A., Hobday, A. J., Holbrook, N. J., Perkins-Kirkpatrick, S. E., Scannell, H. A., Straub, S. C., \& Wernberg, T. (2018). 
Longer and more frequent marine heatwaves over the past century. Nature Communications, 9, 1-12.

Ortiz, J. C., Gomez-Cabrera, M. D. C., \& Hoegh-Guldberg O. (2009). Effect of colony size and surrounding substrate on corals experiencing a mild bleaching event on Heron Island reef flat (southern Great Barrier Reef, Australia). Coral Reefs, 28, 999-1003.

Ortiz, J. C., Wolff, N. H., Anthony, K. R. N., Devlin, M., Lewis, S., \& Mumby, P. J. (2018). Impaired recovery of the great barrier reef under cumulative stress. Science Advances, 4:eaar6127.

R Core Team (2017). R: a language and environment for statistical computing.

Shaw, E. C., Phinn, S. R., Tilbrook, B., \& Steven, A. (2014). Comparability of slack water and Lagrangian flow respirometry methods for community metabolic measurements. PLoS One, 9:e112161.

Siebeck, U. E., Marshall, N. J., Klüter, A., \& Hoegh-Guldberg, O. (2006). Monitoring coral bleaching using a colour reference card. Coral Reefs, 25, 453-460.
Simpson, E. H. (1949). Measurement of diversity. Nature, 163, 688.

Spalding, M., Burke, L., Wood, S. A., Ashpole, J., Hutchison, J., \& Zu Ermgassen P. (2017). Mapping the global value and distribution of coral reef tourism. Marine Policy, 82, 104-113.

Wolanski, E., Andutta, F., Deleersnijder, E., Li, Y., \& Thomas, C. J. (2017). The Gulf of Carpentaria heated Torres Strait and the Northern Great Barrier Reef during the 2016 mass coral bleaching event. Estuarine, Coastal and Shelf Science, 194, 172-181.

Publisher's Note Springer Nature remains neutral with regard to jurisdictional claims in published maps and institutional affiliations. 